\section{The effect of skills training on attitudes, knowledge and clinical uptake of post- placental intra-uterine device use}

\author{
Christine Els, ${ }^{1}$ \\ Johannes L. van der Merwe, ${ }^{1}$ \\ Justin Harvey, ${ }^{2}$ Petrus Steyn ${ }^{1,3}$ \\ 'Department of Obstetrics and \\ Gynaecology, Stellenbosch University and \\ Tygerberg Hospital, Tygerberg; ${ }^{2}$ Centre \\ for Statistical Consultation, Stellenbosch \\ University, Tygerberg, South Africa; \\ ${ }^{3}$ Department of Reproductive Health and \\ Research, World Health Organization, \\ Geneva, Switzerland
}

\section{Abstract}

The objective of the present study is to investigate the effect of skills training on knowledge and attitudes of post-placental intra-uterine device (PPIUD) use, including the uptake thereof, and suggest training proposals. In-service skills training, alongside departmental protocol implementation, on PPIUD insertions were offered to healthcare professionals at Tygerberg Hospital, South Africa. Training was based on The postpartum intrauterine device. A training course for service providers, participant handbook from EngenderHealth (New York, NY, USA). Participants completed a questionnaire at enrolment and after 6 months to assess their knowledge and attitude towards PPIUD use. Most participants reported having the necessary skills to fulfil their family planning responsibilities $(\mathrm{P}<0.01)$, defined by their own perceived ability, and also reported that they could apply what they learnt $(\mathrm{P}<0.01)$. Most health care providers recommended IUDs to post-partum women $(\mathrm{P}=0.03)$, especially those who desire no more children $(\mathrm{P}=0.05)$, resulting in more participants providing IUDs $(\mathrm{P}=0.03)$ that could be attributed to the increased availability of reference material, i.e. training materials $(\mathrm{P}=0.02)$ and protocols $(\mathrm{P}=0.02)$. In conclusion, in-service PPIUD skills training guided by local protocol implementation resulted in an improvement of self-reported competency, counselling and PPIUD insertion. Repeated training with adequate supervision is imperative.

\section{Introduction}

The intra-uterine device (IUD) is the sec- ond most prevalent contraceptive method worldwide (13.6\% among women of reproductive age, married or in union), second only to sterilisation. ${ }^{1}$ Effective post-partum contraception is an absolute necessity especially since many young women commence sexual activity by 6 weeks post-partum, ${ }^{2}$ thus making the optimal time available for initiating an effective, long acting contraceptive method limited.

The safety and efficacy of post-partum IUDs has been proven with large studies and well composed systematic reviews., ${ }^{3,4}$ Immediate post-placental IUD (PPIUD) insertion (within 10 min after placental delivery) has the benefit of instant peace of mind against unplanned pregnancies while being safe ${ }^{5}$ with a low infection rate $^{6}$ favorable side effect profile, ${ }^{5}$ no effect on breastfeeding ${ }^{7}$ and is also cost effective for the health care system. ${ }^{8}$ Yet many health care workers are still misinformed ${ }^{9}$ and most women are not offered the option of having a PPIUD inserted, even though many would have chosen the option. In a local survey Tshivula and Steyn reported that only 5.9\% of pregnant women were counselled on IUDs and only $1.3 \%$ of post-partum women were prescribed an IUD. ${ }^{10}$ Furthermore, a qualitative study in post-partum adolescents noted that a major barrier to IUD uptake in service-level obstacles were the lack of provider training. ${ }^{11}$

The study aim was to investigate the effect of skills training on the knowledge and attitudes of health care providers, secondly to review the uptake of PPIUD and propose a model for future training.

\section{Materials and Methods}

A prospective cohort intervention study was performed at Tygerberg Hospital, a regional referral and academic teaching center in the Western Cape Province, South Africa, providing care to roughly 1.2 million women. The study population consisted of the health care providers of the Department of Obstetrics and Gynaecology involved with antenatal and peripartum care, as they are responsible for reviewing and counselling pregnant women on their future contraceptive need, specifically medical officers (general medical practitioners), registrars (postgraduate obstetric and gynaecology specialists in training), consultants (qualified obstetricians and gynaecologists), and advanced midwives.

After enrolment, a self-administered, anonymous Staff performance and attitude towards post-partum family planning questionnaire comprising of multiple-choice questions [based on EngenderHealth's (New York, NY, USA) the Acquire project] ${ }^{12}$ was completed. This questionnaire served a dual function of evaluating their knowledge and attitude as
Correspondence: Johannes L. van der Merwe, Department of Obstetrics and Gynaecology, Stellenbosch University and Tygerberg Hospital, 19081 Tygerberg, South Africa.

Tel: +27.219385173 .

E-mail: hvdm@sun.ac.za

Key words: Post-placental IUD; Post-partum; Skills training.

Acknowledgements: the authors would like to acknowledge EngenderHealth (New York, NY, USA) for the course material used.

Contributions: CE and JLvdM conceived the study; all authors participated in the study design. Data collection done by CE and JLvdM, and analysis was done by JH. All authors read, edited, and approved the final manuscript.

Conflict of interest: the authors declare no potential conflict of interest.

Received for publication: 21 May 2015. Revision received: 26 July 2015.

Accepted for publication: 26 July 2015.

This work is licensed under a Creative Commons Attribution 3.0 License (by-nc 3.0)

(C) Copyright C. Els et al., 2015

Licensee PAGEPress, Italy

Healthcare in Low-resource Settings 2015; 3:5278 doi:10.4081/hls.2015.5278

well as assessing their needs for providing post-partum family planning. Thereafter, they attended a half-day course on post-partum IUD insertion and use based on EngenderHealth the Acquire project, ${ }^{13}$ which was used with their permission. They were given access to the handbook and a departmental protocol was introduced regarding PPIUD insertion. Participants had to insert the first five IUDs under the supervision of two master trainers. After a six-month period the questionnaire was administered a second time. Answers from the questionnaires were then entered into a tabulated database with summative scores.

Mothers attending the high-risk antenatal clinic received counselling on post-partum contraception and their choice was documented in their maternity case record. Those requesting PPIUD were re-counselled and reviewed for eligibility when they presented in labour. The Copper T380A intrauterine device was used. Primary outcomes were the health care providers' self reported attitude and knowledge on post-partum IUD use. Secondary outcomes included: i) percentage of participants who provide clients with information about all family planning methods; ii) percentage of participants who provide clients with information about post-partum IUD use; iii) percentage of participants who were able to 
provide post-partum IUD use; and iv) number of IUDs inserted post placental.

Statistical analyses were done comparing the combined first to the second questionnaire results using Statistica Version 11 from Statsoft.com (Statsoft, Tulsa, OK, USA). Data were expressed as medians (ranges), means (SD) or n (\%) as appropriate. Categorical data was analysed using the Chi-square test. Where an expected cell value was less than 5 , the Fischer exact test was used. Continuous data was analyzed with Student's T test for parametric and the Mann-Whitney U test for nonparametric data. A P value of $<0.05$ was regarded as significant.

The study was approved and registered by the Human Research and Ethics Committee of Stellenbosch University (S11/11/031).

A review of the literature was performed on training and attitudes of PPIUD insertion of all original articles published before August 1, 2014, by incorporating the following terms in a Medline/PubMed database search: intra-uterine device, IUD, post-partum, post-placental and training. All articles $(\mathrm{n}=419)$, including their references, titles and abstracts were screened for relevance. This identified 111 articles, of which the full text was reviewed. This search strategy yielded a total of 4 original research articles on PPIUD insertion train- ing.

\section{Results}

The study (from 17 February 2012 to 10 January 2013) enrolled fifty participants who completed the first questionnaire (Q1) while 42 completed the second questionnaire (Q2). Participants consisted of consultants $(n=15$, $30 \%)$ and registrars $(n=18,36 \%)$, medical officers $(n=7,14 \%)$ and midwives $(n=10,20 \%)$.

Eight participants did not complete the second questionnaire (three did not participate in training, two changed employment, two were unavailable and one declined to complete the second questionnaire). There were no differences between the characteristics of the first and second questionnaires participants with regards to respective position $(\mathrm{P}=0.37)$, number of months in position $(\mathrm{P}=0.28)$ or in the number of months within the facility $(\mathrm{P}=0.12)$.

Table 1 depicts their expectations, knowledge and skills on family planning. Most indicated that they understood their role in family planning (Q1 86\% and Q2 83\%; $\mathrm{P}=0.72)$ this was mainly due to the training they received (Q1 50\% and Q2 45\%; P=0.65). However only $28 \%$ received training specifically in family planning or reproductive health in the last 2 years. More participants indicated that they had access to reference material to assist them in their family planning responsibilities such as training materials (Q1 14\% and Q2 29\%; $\mathrm{P}=0.02)$ and protocols (Q1 12\% and Q2 31\%; $\mathrm{P}=0.02$ ) in the second questionnaire.

Table 2 depicts the attitudes and practices towards post-partum family planning. The methods most discussed with clients include injectable contraceptives (Q1 98\% and Q2 86\%; $\mathrm{P}=0.04$ ), the IUD (Q1 $90 \%$ and Q2 95\%; $\mathrm{P}=0.35)$ and female sterilization ( $\mathrm{Q} 188 \%$ and $\mathrm{Q} 2$ 78\%; $\mathrm{P}=0.22$ ) synchronously most provided injectable contraceptives (Q1 66\% and Q2 66\%; $\mathrm{P}=0.95)$ and female sterilization, (Q1 58\% and Q2 64\%; $\mathrm{P}=0.54$ ) in the last three months. While more provided IUDs to clients after training (Q1 50\% and Q2 71\%; $\mathrm{P}=0.03$ ). For clients specifically wanting to space their next birth most recommended IUDs (Q1 90\% and Q2 92\%, $\mathrm{P}=0.62)$, injectable ( $\mathrm{Q} 162 \%$ and $\mathrm{Q} 2$ $61 \% ; \mathrm{P}=0.99)$ and oral contraceptives $(\mathrm{Q} 150 \%$ and $\mathrm{Q} 245 \%$; $\mathrm{P}=0.65)$, whereas most recommended female sterilization (Q1 100\% and Q2 100\%; $\mathrm{P}=1.0)$, vasectomy ( $\mathrm{Q} 188 \%$ and $\mathrm{Q} 2$ $88 \% ; \mathrm{P}=0.99)$ and IUDs (Q1 62\% and Q2 80\%; $\mathrm{P}=0.05)$ to women who desire no more children. The methods recommend within the first 48 h post-partum were IUDs (Q1 76\% and Q2

Table 1. Study participants' job expectations, general knowledge and skills.

\begin{tabular}{|c|c|c|c|c|}
\hline & & $\begin{array}{l}\text { Questionnaire } 1 \\
\text { (tot=50) }\end{array}$ & $\begin{array}{l}\text { Questionnaire } 2 \\
\text { (tot=42) }\end{array}$ & P value \\
\hline \multicolumn{2}{|c|}{ Providing family planning services, $n$ (\%) } & $45(90)$ & $40(95)$ & - \\
\hline \multicolumn{2}{|c|}{ Understood their roles/tasks in family planning, $\mathrm{n}(\%)$} & $43(86)$ & $35(83)$ & - \\
\hline Job expectations & $\begin{array}{l}\text { Participants who had access to norms/procedures, } \\
\text { flowcharts or protocols assisting them in family planning tasks, n (\%) }\end{array}$ & $18(36)$ & $21(50)$ & - \\
\hline Knowledge and skills & $\begin{array}{l}\text { Participants who could apply what they learned in these courses, } \mathrm{n}(\%) \\
\text { Participants who felt they had the skills necessary to fulfil their } \\
\text { family planning responsibilities, n (\%) }\end{array}$ & $6(12)$ & $18(43)$ & $<0.01$ \\
\hline
\end{tabular}

Table 2. Study participants' attitudes and practices towards post-partum family planning.

\begin{tabular}{|c|c|c|c|c|}
\hline \multirow{2}{*}{\multicolumn{2}{|c|}{ Counselled/provided information to pregnant women on contraceptives in the last three months, n (\%) }} & $\begin{array}{l}\text { Questionnaire } 1 \\
(\text { tot }=50)\end{array}$ & \multirow{2}{*}{$\begin{array}{l}\text { Questionnaire } 2 \\
\qquad \begin{array}{l}\text { (tot }=42) \\
40(95)\end{array}\end{array}$} & \multirow{2}{*}{$\begin{array}{l}\text { P value } \\
-\end{array}$} \\
\hline & & $49(98)$ & & \\
\hline Methods agreed to be used post-partum (0-48 h), n (\%) & $\begin{array}{l}\text { LAM } \\
\text { Pill } \\
\text { Injectable } \\
\text { Condom } \\
\text { IUD } \\
\text { Female sterilization } \\
\text { Vasectomy }\end{array}$ & $\begin{array}{l}27(54) \\
9(18) \\
33(66) \\
28(56) \\
38(76) \\
36(72) \\
22(44)\end{array}$ & $\begin{array}{l}22(54) \\
15(36) \\
29(69) \\
18(43) \\
38(92) \\
31(75) \\
20(48)\end{array}$ & $\begin{array}{c}- \\
0.05 \\
- \\
- \\
0.04 \\
- \\
-\end{array}$ \\
\hline \multicolumn{2}{|c|}{ Participants who have heard about post-partum insertion of an intrauterine contraceptive device, $\mathrm{n}(\%)$} & $44(88)$ & $38(93)$ & - \\
\hline \multicolumn{2}{|c|}{ Participants who provide information and counselling on STIs and HIV to post-partum women, n (\%) } & $50(100)$ & $40(97)^{\circ}$ & - \\
\hline \multicolumn{2}{|c|}{ Participants who would be willing to provide family planning services to an HIV positive client, n (\%) } & $50(100)$ & $40(97)^{\circ}$ & - \\
\hline \multicolumn{2}{|c|}{ Participants who would be willing to provide family planning services to a person living with AIDS, n (\%) } & $50(100)$ & $40(97)^{\circ}$ & - \\
\hline
\end{tabular}

LAM, lactational amenorrhoea method; IUD, intrauterine device; STIs, sexually transmitted infections; HIV, human immunodeficiency virus; AIDS, acquired immunodeficiency syndrome. ${ }^{\circ}$ One participant did not provide clinical care to post-partum women. 
92\%; $\mathrm{P}=0.03$ ), female sterilization ( $\mathrm{Q} 172 \%$ and $\mathrm{Q} 275 \% ; \mathrm{P}=0.69)$ and injectable contraceptives (Q1 66\% and Q2 69\%; $\mathrm{P}=0.76$ ). Most indicated that all methods of family planning could be used while breastfeeding with injectable contraceptives (Q1 86\% and Q2 90\%; P=0.54), IUDs (Q1 82\% and Q2 87\%; $\mathrm{P}=0.45$ ) and condoms (Q1 72\% and Q2 82\%; $\mathrm{P}=0.21$ ) most frequently endorsed. Most would never recommend lactational amenorrhoea method (LAM) to anyone ( $\mathrm{Q} 166 \%$ and $\mathrm{Q} 266 \% ; \mathrm{P}=0.95)$.

Table 3 depicts their specific knowledge on PPIUD insertion and use. Most specified that IUD insertion is associated with side effects and minor complications, specifically cramping (Q1 78\% and Q2 83\%; $\mathrm{P}=0.52)$ and bleeding (Q1 80\% and Q2 88\%; $\mathrm{P}=0.29$ ), but after training more indicated that intermenstrual spotting can be expected (Q1 50\% and Q2 71\%; $\mathrm{P}=0.04$ ) and fewer noted that IUD insertion is associated with infections (Q1 70\% and Q2 50\%; $\mathrm{P}=0.05$ ). Moreover, most indicated that clients should return to the clinic if they experienced increased bleeding (Q1 74\% and Q2 $76 \% ; \mathrm{P}=0.81)$ and signs of infection (Q1 88\% and $\mathrm{Q} 283 \% ; \mathrm{P}=0.52$ ).

Whilst most indicated that clients should return within three to six weeks after the insertion (Q1 76\% and Q2 85\%; $\mathrm{P}=0.24$ ), some uncertainty remained as nearly $20 \%$ indicated that they should return only after the first normal period (Q1 20\% and Q2 16\%; $\mathrm{P}=0.68$ ).

The questionnaire's final section enquired about the participants perceptions concerning environmental and equipment needs for post- partum IUD insertion. Most felt that although there were sufficient space (Q1 76\% and Q2 $76 \% ; \mathrm{P}=0.96)$ and clean/aseptic work place $(\mathrm{Q} 1$ $58 \%$ and $\mathrm{Q} 271 \% ; \mathrm{P}=0.18$ ), there was a lack of privacy (Q1 65\% and Q2 75\%; $\mathrm{P}=0.29$ ). The majority indicated that they had the equipment and instruments, including supplies, for postpartum IUD insertion (Q1 66\% and Q2 78\%; $\mathrm{P}=0.18$ ) however nearly half of the participants did not to have enough time to offer a practical and manageable post-partum IUD service (Q1 56\% and Q2 45\%; $\mathrm{P}=0.30$ ).

During the year preceding the study 15 PPIUDs were inserted, while in the 6 months of the study intervention 67 PPIUDs were inserted. There were 7576 deliveries during 2012 at this facility.

\section{Discussion}

Across the world the use of long acting reversible contraceptive methods, especially PPIUDs, is being promoted in the puerperium. This study highlighted the importance of inservice training with significant more participants reporting that they had the necessary skills to fulfil their family planning responsibilities $(\mathrm{P}<0.01)$ and could apply what they learnt $(\mathrm{P}<0.01)$. Furthermore, more recommended IUDs to post-partum women ( $\mathrm{P}=0.03)$, especially those who desire no more children $(\mathrm{P}=0.05)$. This resulted in more participants providing IUDs overall $(\mathrm{P}=0.03)$. The effect could be attributed to the increased availability of reference material to assist them in their family planning responsibilities such as training materials $(\mathrm{P}=0.02)$ and protocols $(\mathrm{P}=0.02)$. Although few participants $(28 \%)$ had any recent training in family planning prior to the study, most had good basic knowledge about PPIUD use. Expectedly their knowledge improved especially in terms of timing of placement [within 10 minutes after placental expulsion $(\mathrm{P}<0.01)$ ], side effects (as bleeding/menstrual irregularities are common) and infections rates (a rare event with PPIUD), potentially leading to better counselling skills. Encouraging breast-feeding could be a valuable addition in counselling, as breast-feeding patients experience fewer side effects. ${ }^{14}$

Thiery and colleagues noted a significant difference between skilled and unskilled PPIUD inserters especially in terms of expulsion-, pregnancy- and removal rates. ${ }^{15}$ In the index study less than 5\% had inserted more than 10 in their career, and almost half had never inserted any PPIUD. Banharnsupawat and Rosenfield ${ }^{16}$ reported that expulsion rates decreased as medical staff gained experience, underlining the importance of continuous training and review. Additionally the importance of correct PPIUD insertion technique cannot be overemphasized, as proper technique is another important factor in reducing expulsion rates. The insertion technique which employs a ring forceps was advocated in this study due to reported higher expulsion

Table 3. Study participants' specific knowledge on post-placental intrauterine device use.

\begin{tabular}{|c|c|c|c|c|}
\hline & \multicolumn{2}{|c|}{$\begin{array}{c}\text { Questionnaire } 1 \\
(\mathrm{tot}=50)\end{array}$} & $\begin{array}{l}\text { Questionnaire } 2 \\
\text { (tot=42) }\end{array}$ & P value \\
\hline The specific times that IUDs can be inserted, n (\%) & $\begin{array}{l}\text { Any time that the client is not pregnant } \\
\text { Any time during the menstrual cycle } \\
\text { Immediate post-placental }(<10 \mathrm{~min}) \\
\text { Within } 48 \text { hours of delivery } \\
\text { After six week post-partum } \\
\text { Immediately after abortion or miscarriage }\end{array}$ & $\begin{array}{l}42(84) \\
24(48) \\
36(72) \\
24(48) \\
44(88) \\
30(60)\end{array}$ & $\begin{array}{l}34(82) \\
24(58) \\
39(95) \\
11(26) \\
36(87) \\
30(73)\end{array}$ & $\begin{array}{c}- \\
- \\
<0.01 \\
0.04 \\
- \\
-\end{array}$ \\
\hline $\begin{array}{l}\text { The longest time delay participants would allow before } \\
\text { inserting a post-partum IUD, } \mathrm{n}(\%)\end{array}$ & $\begin{array}{l}10 \text { seconds } \\
10 \text { minutes } \\
12 \text { hours } \\
24 \text { hours }\end{array}$ & $\begin{array}{l}2(4) \\
17(34) \\
8(16) \\
16(32)\end{array}$ & $\begin{array}{c}0(0) \\
27(65) \\
2(4) \\
10(24)\end{array}$ & $\begin{array}{c}- \\
<0.01 \\
- \\
-\end{array}$ \\
\hline The IUDs can fall out, $\mathrm{n}(\%)$ & & $45(90)$ & $40(97)$ & \\
\hline The chance of falling pregnant with an IUD is, $n(\%)$ & $\begin{array}{l}\text { No chance } \\
\text { Very high } \\
\text { The same as sterilization } \\
\text { The same as using a condom }\end{array}$ & $\begin{array}{c}2(4) \\
1(2) \\
46(92) \\
1(2)\end{array}$ & $\begin{array}{l}0(0) \\
0(0) \\
40(97) \\
0(0)\end{array}$ & $\begin{array}{l}- \\
- \\
- \\
-\end{array}$ \\
\hline The IUD does offer protection against STIs and HIV infe & & $0(0)$ & $3(7)$ & 0.08 \\
\hline The participants that would insert an IUD in an HIV & & $39(78)$ & $38(92.6)$ & 0.05 \\
\hline The number of IUD devices participants inserted, $n(\%)$ & $\begin{array}{l}0 \\
1-10 \\
11-25 \\
>25\end{array}$ & $\begin{array}{l}24(48) \\
21(42) \\
1(2) \\
2(4)\end{array}$ & $\begin{array}{l}17(41) \\
21(51) \\
2(4) \\
0(0)\end{array}$ & $\begin{array}{l}- \\
- \\
-\end{array}$ \\
\hline Would recommend an IUD to their wife, sister, daughter & & $48(96)$ & $41(100)$ & - \\
\hline
\end{tabular}

IUD, intrauterine device; STIs, sexually transmitted infections; HIV, human immunodeficiency virus. 
rates with hand insertion ${ }^{17}$ although this finding was not validated in systematic reviews. ${ }^{3}$ Irrespective of the technique used, emphasis should be put on high fundal placement.

PPIUD insertions can be performed safely and effectively within a training program, but the safety profile, complication and side effect rates are dependant on the level of training and supervision. ${ }^{18}$ Intensive training (over a nine day period) with supervised insertions ${ }^{19}$ or repeated training ( 6 weekly) aided by ultrasound-guided insertions ${ }^{18}$ resulted in a more effective service. The incorporation of ultrasound assessment post insertion could also be a valuable tool to further improve clinical care but this would come at the cost of additional equipment, training and time per insertion. Accumulative expulsion and missing strings rate of 10 and $11 \%$ respectively were seen in larger programs. ${ }^{20}$ The fact that only theoretical training and protocol implementation with supervision but no model training was done could be criticised as model training was beneficial in the training program of Prager and colleagues. ${ }^{19}$

The participants in the index study consisted mostly of doctors and this raises the question whether the emphasis should have been placed on training midwives, as they are better positioned for a PPIUD service. This high doctor ratio possibly contributed to the majority of PPIUDs being cited during caesarean deliveries. Insertions during caesarean sections are well recognized to have lower expulsion rates ${ }^{3}$ (than after vaginal deliveries) and were not as dependent on provider experience. ${ }^{14}$ However, discontinuation rates after caesarean PPIUD can be as high as $40 \%$ at 1 year follow up and the frequent side effect of missing strings have been well documented. ${ }^{5,21}$

Furthermore the low vaginal insertion rate can be explained by the lack of having a master trainer available at all times in the labour ward (as the master trainers also had other responsibilities), and it is easier to arrange supervision during a planned or urgent caesarean delivery than within the 10 min after a vaginal delivery. This possibly discouraged participants to prepare for vaginal insertion. The lack of time available for setup and counselling during routine vaginal deliveries could also have played a role as nearly half of the participants felt that they did not have the time to offer a post placental IUCD service (Q1 56\% and Q2 $45 \% ; \mathrm{P}=0.30$ ). Training more master trainers, utilising a family planning counsellor as well as having vaginal delivery packs that include the necessary equipment specifically for PPIUD could make the program more efficient.

PPIUD integration into an existing family planning program have also been reported from the African continent, ${ }^{22}$ yet the a lack of knowledge, low IUD prevalence and cultural factors such as husband disapproval still lead to low overall PPIUD uptake as this could further explain the low vaginal insertion rate seen in the index study. ${ }^{23}$

A largely neglected strategy to avert motherto-child HIV transmission is pregnancy prevention by voluntary use of contraception in HIVpositive women. Most women irrespective of their HIV status still had poor knowledge of long acting methods and $60 \%$ still reported that their last pregnancy was unplanned. ${ }^{24}$ In the index study there was a significant increase in the number of participants that would insert an IUD in an HIV positive patient $(\mathrm{P}=0.05)$. Evidence regarding the safety of intrauterine contraceptive use among women with HIV remains limited, but is generally reassuring regarding adverse health effects, disease transmission to uninfected partners, and disease progression. ${ }^{25}$

The study method utilised in the index study could be a unique approach to improve postpartum contraceptive awareness and clinical uptake. Furthermore the high participant completion rate (84\%) is an indication that most health care providers saw this an area of need and essential training.

A major limitation was the subjective nature of this study, without an objective assessment of the health care workers to validate their responses. Also this study did not reflect on the clinical outcomes of the PPIUD insertions, highlighting the need for further research to investigate the clinical significance of self reported PPIUD skills (a study in progress). A previous systematic review noted that the clinical benefit of small studies like this might be short lived and that bigger high-quality studies with supply-side approaches ( $v s$ demand side) using integrated programs have long-term impacts. $^{26}$

\section{Conclusions}

This study was done in answer to the shortcoming of in-service training of permanent staff, as well as the lack of long-term post-partum contraceptive choices. It demonstrated that healthcare workers could have a better self-reported understanding and skill acquisition with in-service training and supervision, in this case specifically in PPIUD. The challenge will be to facilitate a continuous training platform on post-partum family planning with focus on all health care staff (especially midwives) utilising model insertions. The incorporation of family planning counsellors and PPIUD ready delivery packs could further enable the service.

\section{References}

1. d'Arcangues C. Worldwide use of intrauterine devices for contraception. Contraception 2007;75:S2-7.

2. Lewis LN, Doherty DA, Hickey M, Skinner SR. Implanon as a contraceptive choice for teenage mothers: a comparison of contraceptive choices, acceptability and repeat pregnancy. Contraception 2010;81:421-6.

3. Grimes DA, Lopez LM, Schulz KF, et al. Immediate post-partum insertion of intrauterine devices. Cochrane Db Syst Rev 2010;5:CD003036.

4. Kapp N, Curtis KM. Intrauterine device insertion during the postpartum period: a systematic review. Contraception 2009;80: 327-36.

5. Kittur S, Kabadi YM. Enhancing contraceptive usage by post-placental intrauterine contraceptive devices (PPIUCD) insertion with evaluation of safety, efficacy, and expulsion. Int J Reprod Contracept Obstet Gynecol 2012;1:26-32.

6. Welkovic S, Costa LO, Faundes A, et al. Post-partum bleeding and infection after post-placental IUD insertion. Contraception 2001;63:155-8.

7. Goldstuck ND, Steyn PS. Intrauterine contraception after cesarean section and during lactation: a systematic review. Int $\mathrm{J}$ Womens Health 2013;5:811-8.

8. Rodriguez MI, Evans M, Espey E. Advocating for immediate postpartum LARC: increasing access, improving outcomes, and decreasing cost. Contraception 2014;90:468-71.

9. Madden T, Allsworth JE, Hladky KJ, et al. Intrauterine contraception in Saint Louis: a survey of obstetrician and gynecologists' knowledge and attitudes. Contraception 2010;81:112-6.

10. Tshivula F, Steyn PS. The knowledge and attitudes of antenatal patients towards intra-uterine contraceptive devices. Specialist Forum 2007;6:10-8.

11. Weston MR, Martin SL, Neustadt AB, Gilliam ML. Factors influencing uptake of intrauterine devices among postpartum adolescents: a qualitative study. Am J Obstet Gynecol 2012;206:e1-7.

12. The ACQUIRE Project. Improving the use of long-term and permanent methods of contraception in Guinea: a performance needs assessment. New York, NY: The ACQUIRE Project/EngenderHealth; 2005.

13. The ACQUIRE Project. The postpartum intrauterine device: a training course for service providers. Trainer's manual. New York, NY: EngenderHealth; 2008.

14. Chi IC. Postpartum IUD insertion: timing, route, lactation, and uterine perforation. 
In: Bardin CW, Mishell DR Jr, eds. Proceedings from the Fourth International Conference on IUDs, Boston, MA, USA. London: Butterworth-Heinemann;1994. pp 219-27.

15. Thiery M, Van Kets H, Van Der Pas H. Immediate postplacental IUD insertion: the expulsion problem. Contraception 1985;31:331-49.

16. Banharnsupawat L, Rosenfield AG. Immediate postpartum IUD insertion. Obstet Gynecol 1971;38:276-85.

17. Apelo RA, Waszak CS. Postpartum IUD insertions in Manila, Philippines. Adv Contracept 1985;1:319-28.

18. Jatlaoui TC, Marcus M, Jamieson DJ, et al. Postplacental intrauterine device insertion at a teaching hospital. Contraception 2014;89:528-33.

19. Prager S, Gupta P, Chilambwe J, et al.
Feasibility of training Zambian nurse-midwives to perform postplacental and postpartum insertions of intrauterine devices. Int J Gynecol Obstet 2012;117:243-7.

20. Shukla M, Qureshi S, Chandrawati. Postplacental intrauterine device insertion: a five year experience at a tertiary care centre in north India. Indian $\mathrm{J}$ Med Res 2012;136:432-5.

21. Eroğlu K, Akkuzu G, Vural G, et al. Comparison of efficacy and complications of IUD insertion in immediate postplacental/early postpartum period with interval period: 1 year follow-up. Contraception 2006;74:376-81.

22. Morrison C, Waszak C, Katz K, et al. Clinical outcomes of two early postpartum IUD insertion programs in Africa. Contraception 1996;53:17-21.

23. Bryant AG, Kamanga G, Stuart GS, et al.
Immediate postpartum versus 6-week postpartum intrauterine device insertion a feasibility study of a randomized controlled trial. Afr J Reprod Health 2013; 17:72-9.

24. Credé S, Hoke T, Constant D, et al. Factors impacting knowledge and use of long acting and permanent contraceptive methods by postpartum HIV positive and negative women in Cape Town, South Africa: a cross-sectional study. BMC Public Health 2012;12:197.

25. Curtis KM, Nanda K, Kapp N. Safety of hormonal and intrauterine methods of contraception for women with HIV/AIDS: a systematic review. AIDS 2009;23:S55-67.

26. Mwaikambo L, Speizer IS, Schurmann A, et al. What works in family planning interventions: a systematic review. Stud Fam Plann 2011;42:67-82. 